\title{
Effect of Aerobic Exercise in Positive and Negative Symptoms in Schizophrenia
}

\author{
Nazli Mahdinasari Nasution ${ }^{1 *}$ (D), Elmeida Effendy ${ }^{1}$ (D), Mustafa Mahmud Amin ${ }^{1}$, Ice Ratnalela Siregar ${ }^{2}$ \\ ${ }^{1}$ Department of Psychiatry, Faculty of Medicine, Universitas Sumatera Utara, Medan, Indonesia; ${ }^{2}$ Politeknik Kesehatan \\ Kementerian Kesehatan Medan, Medan, Indonesia
}

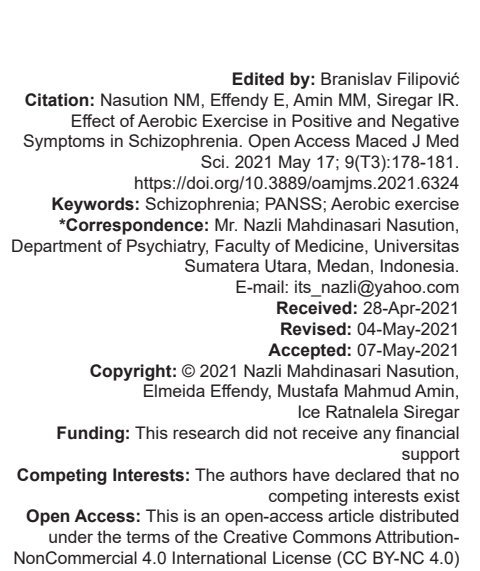

Introduction

Schizophrenia is a severe mental disorder that impacts on the individual and society. The prevalence of schizophrenia is approximately $0.7-1 \%$. It is one of the leading causes of disability in young adults. It is characterized by positive, negative, cognitive, affective, and aggressive symptoms. Negative symptoms such as alogia, blunted affect, anhedonia, avolition, and apathy. It can occur in all stages and lead disability throughout life. It causes burden for patient, family, and health-care system. This condition has a detrimental influence on the ability of schizophrenic patients to work across all facets of everyday life, making it a significant clinical goal that cannot be handled with antipsychotics in a sufficient manner [1], [2], [3].

Systematic reviews indicate that aerobic exercise decreases positive, negative, and secondary symptoms such as depression, low self-esteem, and social withdrawal. A meta-analysis of aerobic exercise recently indicated that for people with schizophrenia, daily physical activity is suitable. Aerobic activity has positive effects on schizophrenics' physical and mental well-being, but there is currently insufficient evidence to support or refute aerobic use as a supplementary intervention [4].

Several studies have shown a positive correlation between exercise and reduction in negative affect. The effect of physical activity on mental health is a complex phenomenon that is clarified by the hypothesis of endorphins, pituitary gland-released endogenous opioids that are believed to cause analgesic effects, euphoric stimulation and have a reward function (they affect the additional release of serotonin, norepinephrine, dopamine, and acetylcholine) and decrease depression, anxiety, and reward levels [5].

\section{Methods}

The implementation of this study includes preparation, data collection, data processing, and preparation of study results. The preparation stage includes obtaining a research permit from the ethics committee of the Faculty of Medicine, Universitas Sumatera Utara. 
The design of the study was an experimental study with non-randomized pre-test and post-test design, and purposive sampling method.

This study was conducted at Prof. Dr. M. Ildrem Mental Hospital in 2016, with the inclusion criteria for schizophrenic patients, according to the $10^{\text {th }}$ revision of the International Statistical Classification of Diseases and Related Problems, female, chronic, and total scores of positive and negative syndrome scales (PANSS) were 60-80, age 18-40 years, body mass index 18.5$25 \mathrm{~kg} / \mathrm{m}^{2}$, and received risperidone $6 \mathrm{mg}$. The exclusion criteria were having a general medical condition.

To measure positive and negative symptoms, we used PANSS. Data collection was preceded by screening using inclusion and exclusion criteria. Then, 34 participants who meet the inclusion criteria will be divided into two groups, intervention group and control group. The intervention group consisted of 17 participants and the control group consisted of 17 participants. Aerobic exercise will be carried out by participants by following the movements of a trained gymnastics instructor. Each participant in the intervention group was given aerobic exercise with a frequency of 3 times a week, with a duration of each session of $45 \mathrm{~min}$ (10 min of warm-up, $25 \mathrm{~min}$ of core, and $10 \mathrm{~min}$ of cooling). Before exercise session, we measured blood pressure, heart rate, and $\mathrm{O} 2$ saturation. Then, we measured again for heart rate and $\mathrm{O} 2$ saturation in each stage, to evaluate the performance of this aerobic exercise. At the end of the study, the PANSS score assessment will be conducted again. Furthermore, data processing will be carried out.

Data were analyzed using Statistical Package for the Social Sciences. Using the Shapiro-will test, normality tests were carried out on the data from each group. Two groups of unpaired numerical comparative groups, if the data distribution is normally distributed in such a way that the independent-t-test is carried out. If the data distribution is not normally distributed, the data transformation is carried out, after which the normality test is carried out again if the data are not normally distributed, then the Mann-Whitney U-test is the analysis performed.

\section{Results}

There was no difference in age between intervention group and control group ( $p=0.79)$. The mean age of intervention group was $33.18 \pm 5.55$ years. The mean age of control group was $33.41 \pm 5.73$ years. There was no difference in duration of illness between intervention group and control group ( $p=0.942)$. The mean duration illness in intervention group was 6.35 \pm 1.84 years. The mean duration of illness in control group was $6.41 \pm 2.00$ years. There was no difference in age of onset between intervention group and control group $(p=0.741)$. The mean age of onset in intervention group was $27.12 \pm 5.81$ years. The mean age of onset in control group was $27.00 \pm 5.86$ years There was no difference in body mass index between intervention group and control group ( $p=0.262)$. The mean body mass index of intervention group was 22.41 $\pm 1.62 \mathrm{~kg} / \mathrm{m}^{2}$. The mean body mass index of intervention group was $21.61 \pm 1.96 \mathrm{~kg} / \mathrm{m}^{2}$ (Table 1 ).

Table 1: Demographic characteristic of participants

\begin{tabular}{|c|c|c|c|}
\hline Variable & Intervention group $(\mathrm{n}=17)$ & Control group $(n=17)$ & $\mathrm{p}$ \\
\hline \multicolumn{4}{|l|}{ Age } \\
\hline Mean \pm SD & $33.18 \pm 5.55$ & $33.41 \pm 5.73$ & $0.790^{\circ}$ \\
\hline \multicolumn{4}{|l|}{ Education level } \\
\hline Low educational level & $9(52.94)$ & $6(35.29)$ & $0.490^{*}$ \\
\hline Higher educational level & $8(47.06)$ & $11(64.71)$ & \\
\hline \multicolumn{4}{|l|}{ Duration of illness } \\
\hline Mean \pm SD & $6.35 \pm 1.84$ & $6.41 \pm 2.00$ & $0.942^{*}$ \\
\hline \multicolumn{4}{|l|}{ Age of onset } \\
\hline Mean \pm SD & $27.12 \pm 5.81$ & $27.00 \pm 5.86$ & $0.741^{*}$ \\
\hline \multicolumn{4}{|l|}{ Body mass index } \\
\hline Mean \pm SD & $22.41 \pm 1.62$ & $21.61 \pm 1.96$ & $0.262^{\circ}$ \\
\hline
\end{tabular}

There was no difference in total score of PANSS between intervention group and control group $(p=0.360)$. The mean total score of PANSS in intervention group was $70.82 \pm 4.73$. The mean total score of PANSS in control group was $69.82 \pm 5.60$. There was no difference in positive score of PANSS between intervention group and control group $(p=0.680)$. The mean positive score of PANSS in intervention group was $16.47 \pm 2.45$. The mean positive score of PANSS in control group was $15.29 \pm 2.37$.

Table 2: Baseline data

\begin{tabular}{llll}
\hline Parameters & Intervention group & Control group & $\mathrm{p}$ \\
\hline Total score of PANSS & $70.82 \pm 4.73$ & $69.82 \pm 5.60$ & $0.360^{*}$ \\
Positive score of PANSS & $16.47 \pm 2.45$ & $15.29 \pm 2.37$ & $0.680^{*}$ \\
Negative score of PANSS & $23(18-26)$ & $21(19-28)$ & $0.329^{* *}$ \\
\hline${ }^{*}$ Independent--t-test, ${ }^{* *}$ Mann-Whitney U-test, PANSS: Positive and negative syndrome scales. &
\end{tabular}

There was no difference in negative score of PANSS between intervention group and control group $(p=0.329)$. The median negative score of PANSS in intervention group was 23 . The maximum and minimum of negative scores in intervention group were 18-26. The median negative score of PANSS in intervention group was 21 . The maximum and minimum of negative scores in control group were 19-28 (Table 2).

The mean change in positive score of PANSS in the intervention group was $4.35 \pm 1.50$ and in the control group was $2.50 \pm 1.99$ with a value of $p<0.001$ which showed a significant difference between the two groups.

The mean change in negative score of PANSS in the intervention group was $3.94 \pm 0.97$ and in the control group was $2.39 \pm 1.04$ with a value of $p<0.001$ which showed a significant difference between the two groups (Table 3).

Table 3: Change in positive and negative score of PANSS

\begin{tabular}{lll}
\hline Parameters & $\begin{array}{l}\text { Mean } \pm \text { Standard deviation/ } \\
\text { Median (Min-Max) }\end{array}$ & $\mathrm{p}$ \\
\hline Change in positive score of PANSS & $4(2-7)$ & $<0.001^{*}$ \\
$\quad$ Intervention group & $2(1-4)$ & \\
$\quad$ Control group & & $<0.001^{* *}$ \\
$\begin{array}{l}\text { Change in negative score of PANSS } \\
\quad \text { Intervention group }\end{array}$ & $13.35 \pm 2.76$ & \\
$\quad$ Control group & $7.88 \pm 1.93$ & \\
${ }^{*}$ Mann-Whitney U-test, **Independent t-test, PANSS: Positive and negative syndrome scales. &
\end{tabular}




\section{Discussion}

The exercise given in this study lasted $45 \mathrm{~min}$, which was performed 3 times a week (135 min per week). This is consistent with a systematic review and metaanalysis conducted by Firth et al., which suggests that 90 min of moderate-to-heavy intensity exercise per week can improve fitness, reduce positive and negative symptoms and improve cognition. A review by Exercise and Sport Science Australia also suggests that interventions carried out at least 90 min per week with moderate to severe intensity can be effective in overcoming mental health problems [6]. Holley suggests that a minimum exercise session of 20-30 min to maintain physical fitness as a healthy lifestyle [7]. This is also in accordance with the guidelines for physical activity and exercise on mental disorders stated by Morgan et al. that for 30 min with moderate activity [8]. In this study, the mean intensity was $63.50 \% \pm 4.79 \%$ (moderate intensity). A meta-analysis of aerobic exercise found that daily physical activity is feasible and has a positive impact on physical and mental health for people with schizophrenia [5].

From this study, it was obtained a significant difference between changes in positive scores of PANSS.

This is consistent with a study where it is stated a reduction in positive and negative symptoms in schizophrenic patients after aerobic exercise compared to a control group [1], [9]. Few studies have assessed the effect of exercise on positive symptoms of schizophrenia. A study conducted by Carter-Morris and Faulkner suggested that exercise can control auditory hallucinations which suggest that exercise can reduce some of the chronic psychotic symptoms [9]. A study conducted by Acil et al. in 2008 which provided aerobic exercise for 30 schizophrenic patients, which suggested that aerobic exercise led to a significant reduction in positive symptoms of the intervention group [10]. In Chamove's study of 40 schizophrenic patients in a Scottish psychiatric nursing home, there was a decrease in psychotic symptoms observed by trained staff [11]. Further conclusions can be explored from the coping strategy of schizophrenic patients. For example, $78 \%$ of schizophrenic patients reported exercising in various ways to reduce hallucinations [9]. Faulkner and Biddle have found that physical exercise is effective in minimizing schizophrenia's negative symptoms and physical activity also serves as a supportive symptom coping mechanism, such as auditory hallucinations [7].

From this study, it was obtained a significant difference between the changes in negative scores of PANSS.

This is also consistent with a study conducted by Wu et al., which found a significant reduction in the general psychopathology score, negative score, and total PANSS score. In their study, there was a large change in rapport poverty and lack of spontaneity [12].
This is also in accordance with a study conducted by Acil et al. They found improvement in negative symptoms [10]. Faulkner proposed that several studies reported an improvement of negative symptoms such as social interest and self-esteem [9].

Firth et al. suggested that moderate to heavy intensity of exercise can improve positive and negative symptoms [6]. Portugal et al. suggested that exercise, leading to improvements in metabolism, oxygenation, and blood flow in the brain, promotes changes in the human brain. Animal studies show that exercise regulates neurotransmitters such as norepinephrine, dopamine, and serotonin. Other neurochemical factors that may be released during exercise include opioids and endocannabinoids that cause euphoria sensations and well-being, anxiolytic effects, sedation, and human pain sensitivity decreases [13].

The proposed exercise mechanism of action is split into two categories: Physiological and psychological factors. Changes in metabolism and the availability of neurotransmitters and sleep control are physiological mediators of the association between exercise and mental health. Changes in dealing with self-efficacy and disruption of negative feelings were psychological mediators [14].

To preserve optimal brain function, exercise will stimulate neurogenesis, modulate synaptic plasticity and improve multiple neurotrophic factors. Animal studies have shown that exercise contributes to improved hippocampal neurogenesis and increased synaptic plasticity. These effects are induced by a rise in many brain growth factors, such as the neurotrophic factor derived from the brain. Changes in brain volume and integrity are also correlated with exercise. Dauwan et al. analyzed 29 studies with data for 1109 patients whose exercise had an effect on overall symptoms and negative symptoms with medium effect sizes and small effect sizes for overall symptoms and positive symptoms [15]. Based on the study by Stathopoulou et al., animals have shown that physical activity causes adaptive downregulation of serotonin receptors, particularly the $5-\mathrm{HT} 2 \mathrm{C}$ receptor [14].

\section{Conclusion}

There is a significant change in positive and negative score of PANSS between intervention group and control group.

\section{References}

1. Malchow B, Reich-Erkelenz D, Oertel-Knochel V, Keller K, Hasan A, Schmitt A, et al. The effects of physical exercise in 
schizophrenia and affective disorders. Eur Arch Psychiatry Clin Neurosci. 2013;263(6):451-67. https://doi.org/10.1007/ s00406-013-0423-2

PMid:23873090

2. Owen MJ, Sawa A, Mortensen PB. Schizophrenia. Lancet. 2016;388(10039):86-97. https://doi.org/10.1016/ s0140-6736(15)01121-6

PMid:26777917

3. Scheewe TW, Backx FJ, Takken T, Jorg F, van Strater AC, Kroes AG, et al. Exercise therapy improves mental and physical health in schizophrenia: A randomized controlled trial. Acta Psychiatr Scand. 2012;127(6):464-73. https://doi.org/10.1111/acps.12029 PMid:23106093

4. Sharkey JL. Exercise and mental health-Implications for treatment: A review of the literature. Couns Wellness J. 2016;5:1-7.

5. Vancampfort D, Probst M, Skjaerven LH, Catalan-Matamoros D, Lundvick-Gylensten A, Gomez-Conesa A, et al. Systematic review of the benefits of physical therapy within a multidisciplinary care approach for people with schziphrenia. Am Phys Ther Assoc. 2012;92(1):11-23. https://doi.org/10.2522/ptj.20110218 PMid:22052946

6. Firth J, Cotter J, Elliot R, French P, Yung AR. A systematic review and meta-analysis of exercise interventions in schizophrenia patients. Psychol Med. 2015;45(7):1343-61. https://doi. org/10.1017/s0033291714003110 PMid:25650668

7. Holley J, Crone D, Tyson P, Lovell G. The effects of physical activity on psychological well-being for those with schizophrenia: A systematic review. Br J Clin Psychol. 2011;50(1):84-105. https://doi.org/10.1348/014466510x496220

PMid:21332522

8. Morgan AJ, Perker AG, Alvarez-Jimenez M, Jorm AF. Exercise and mental health: An exercise and sports science Australia commissioned review. J Exerc Physiol. 2013;16(4):64-73.

9. Faulkner GE. Exercise as an adjunct treatment for schizophrenia In: Faulkner GE, Taylor AH, editors. Exercise, Health and Mental Health Emerging Relationships. $1^{\text {st }}$ ed. New York: 2005. p. 27-42. https://doi.org/10.4324/9780203415016_chapter_3

10. Acil AA, Dogan S, Dogan O. The effects of physical exercises to mental state and quality of life in patients with schizophrenia J Psychiatry Ment Health Nurs. 2008;15(10):808-15. https://doi. org/10.1111/j.1365-2850.2008.01317.x

11. Martinsen EW, Taube J. Schizophrenia. In: Physical activity in the prevention and treatment of disease. $2^{\text {nd }}$ ed. Sweden: Swedish National Institute of Public Health; 2010. p. 579-88.

12. Wu MH, Lee CP, Hsu SC, Chang CM, Chen CY. Effectiveness of high-intensity interval training on the mental and physical health of people with chronic schizophrenia. Neuropsychiatr Dis Treat. 2015;11:1255-63.

PMid:26060400

13. Portugal EM, Cevada T, Monteiro-Junior RS, Guimaraes GG, Rubini EC, Lattari E. Neuroscience of exercise: from neurobiology mechanisms to mental health. Neuropsychobiology. 2013;68(1):1-14. https://doi.org/10.1159/000350946 PMid:23774826

14. Stathopoulou G, Powers MB, Berry AC, Smiths JA, Otto MW. Exercise interventions for mental health: A quantitative and qualitative review. In: Clinical Psychology Science and Practice. 2006; 13:179-193. https://doi. org/10.1111/j.1468-2850.2006.00021.x

15. Dauwen M, Begemann MJ, Heringa SM, Sommer IE. Exercise improves clinical symptoms, quality of life, global funtioning, and depression in schizophrenia: A systematic review and meta-analysis. Schizophr Bull. 2016;42(3):588-99. https://doi. org/10.1093/schbul/sbv164

PMid:26547223 